Moskvin Victor Anatolyevich, Russian University of Physical Education, Sport, Youth and Tourism, Dr.Psych., professor of psychology department E-mail:1700018v@mail.ru

Moskvina Nina Victorovna, Ph.D., associate professor of psychology department Shumova Natalya Sergeyvna, Ph.D., associate professor of psychology department Kovalevski Andrey Grigoryevich, postgraduate student of psychology department

\title{
Tendency to risk and impulsiveness at students of sports university
}

Abstract: Investigated the propensity to risk, and impulsivity in example sports University students (aged 17-18 years, $\mathrm{n}=80$ ) with different signs of asymmetry of the regulatory unit of the brain. To assess the propensity to risk questionnaire applied A. Shmelev, and to assess the impulsiveness questionnaire V. Losenkov. Set the individual characteristics of the inclination to impulsiveness students caused from asymmetries of the brain.

Keywords: individual differences, asymmetry, risk aversion, impulsiveness.

$$
\begin{array}{r}
\text { Москвин Виктор Анатольевич, } \\
\text { Российский государственный университет } \\
\text { физиеской культуры, спорта, молодежи и туризма, } \\
\text { д.псх.н., профессор кафедры психологии } \\
\text { E-таіl: 1700018v@таі.ги } \\
\text { Москвина Нина Викторовна, } \\
\text { к.псх. н., доиент кафедры психологии } \\
\text { Шумова Наталия Сергеевна, } \\
\text { к.псх. н., доиент кафедры психологии } \\
\text { Ковалевский Андрей Григорьевич, } \\
\text { аспирант кафедры психологии }
\end{array}
$$

\section{Склонность к риску и импульсивность у студентов спортивного университета}

Аннотация: Исследованы скмонность к риску и импульсивность на примере студентов спортивного вуза (в возрасте 17-18 мет, $\mathrm{n}=80$ ) с разными признаками асимметрии регумятивного блока мозга. Аля оценки скмонности к риску применялся опросник А. Г. Шмелева, а Амя оценки импульсивности - опросник В. А. Аосенкова. Установлены индивидуальные особенности скцонности к импульсивности у студентов, обусловменные межполушарными асимметриями.

КАючевые слова: индивидуальные размичия, асимметрия, скмонность к риску, импульсивность.

Введение. В современной спортивной психологии одно из важных мест занимает проблема волевой регумяции, скмонности к риску и импульсивному поведению [3-7]. Произвольная регуляция имеет индивидуальные особенности, которые могут быть обусловлены и психофизиологическими параметрами. В работе изучен вопрос о связях индивидуальных особенностей склонности к риску и импульсивности у лиц с разными вариантами функциональных асимметрии мозга (ФАМ).

Сегодня в современной науке на стыке Аифференциальной психофизиологи и нейропсихологии успешно развивается такое новое направление как нейропсихо- могический похоА к проблеме инАивидуамьных размичий [3-6]. Проблема связи показателей функционамьной асимметрии с индивидуально-психологическими характеристиками человека представляет большой интерес и Аля решения ряАа проблем спортивной психологии. В настоящее время исследована проблема цеворукости в спорте высших Аостижений [4]. Исследованы индивидуальные особенности волевой регумяции на примере студентов спортивного вуза [5-7]. Н. В. Москвина выявика закономерную связь межАу когнитивными стилями («полезависимость-поленезависимость») и матерамьными профимями испытуемых, установмено, 
что мица с Аоминирующим мевым полушарием явцяются более поменезависимыми [8].

Аля решения проблемы исследования связи психофизиологических параметров (индивидуальных особенностей функциональных асимметрий) с регулятивными процессами человека (в виде индивидуальных особенностей склонности к риску и импульсивности), нами была поставлена цемь: изучить индивидуальные особенности этих функций уздоровых испытуемых с разными вариантами асимметрий.

Методы и организация исследования. В эксперименте приняли участие 80 студентов 2 курса РГУФКСМиТ в возрасте 17-18 ^ет, из них 44 юношей и 36 девушки. По спортивному мастерству в выборке было 1 мсмк, 3 мс, 10 кмс, 66 человек имели 1 разряа.

Исследование индивидуально-психологических особенностей испытуемых проводилось с помощью следующих тестов: опросника А.Г.Шмелева (направленного на оценку склонность к риску) и опросника В.А. Аосенкова, направменного на оценку импульсивности. Опросник А.Г. Шмелева содержит 50 вопросов, из них 10 относятся к шкале «искренности» (или шкале «лжи»), таким образом, на оценку склонности к риску направлено 40 вопросов, на которые испытуемому необходимо дать утвердительный или отрицательный ответ. Цель опросника - получить показатель величины склонности к риску как черты характера. Тестопросник В.А. Аосенкова состоит из 20 вопросов, к кажАому из которых Аается четырехбальная шкала ответов, Импульсивность рассматривается автором как черта, противоположная волевым качествам целеустремленности и настойчивости.

В числе методик Аиагностики межполушарных отношений использовались: показатели пациального Аоминирования по А.Р. Аурия [2], в т. ч. показатель пробы «перекрест» рук (ПППР), который по Аанным ЭЭГ отражает парциальное Аоминирование контрлатеральных мобных отделов мозга и имеет отношение к третьему блоку мозга, осуществляющему функции планирования, контромя и регумяции деятельности [3-6; 9]. Статистическая обработка Аанных исследования проводилась с использованием критерия Стьюдента.

Результаты и их обсуждение. При анализе результатов психодиагностического тестирования выборка студентов спортивного вуза $(\mathrm{n}=80)$ были разделены на Аве поАгруппы с разными показатемями пробы «перекрест рук» (ПППР) - правыми $(\mathrm{n}=33)$ и мевыми $(\mathrm{n}=47)$.

Анализ параметров показац, что достоверных размичий по обеим шкалами опросника А.Г. Шмелева в поАгруппах с правыми и мевыми ПППР выявлено не было. В то же самое время, отмечаются более высокие значения «импульсивности» в поАгруппе с мевыми ПППР по сравнению с правыми (49,38 и 46,97 б. соответственно, $\mathrm{p}<0,05)$ в опроснике В.А. Аосенкова.

Когнитивные стили «рефмексивность-импульсивность» быливыдемены Аж. Каганомпри изучении интемлектуальной Аеятельности, когда в условиях неопределенности нужно было принять решение и требовалось осуществить правильный выбор из некоторого множества альтернатив.
Импульсивные мюди хотят Аобиваться быстрого успеха, отчего склонны быстро реагировать на проблемную ситуацию. ОАнако при этом гипотезы выАвигаются и принимаются ими без тщательного продумывания, поэтому часто оказываются неверными. Аля рефмексивных мюдей, напротив, характерно замеАленное реагирование в такой ситуации, решение принимается на основе тщательного взвешивания всех «за» и «против». Импульсивные хуже, чем рефмексивные, справмяются с заданиями на решение проблем, где не указаны альтернативы ответов. Рефлексивные более поленезависимы, чем импульсивные. У них выше устойчивость внимания. Импульсивные обладают меньшим самоконтромем, низкой концентрацией внимания, но большим его объемом [4-6]. ПоА готовностью к риску можно понимать потенциал субъекта, проявляющийся в стремлении Аействовать в ситуациях неопределенности, и он успешно реализуется тогАа, когАа есть возможность снизить эту неопределенность с помощью когнитивных и мичностных усилий. ПоА импульсивностью понимаются Аействия и решения, принятые по первому побуждению, без предварительного анализа ситуации (такие решения также можно назвать эмоциональными). Если рассматривать такое мичностное свойство, как склонность криску, то поА ним можно понимать также стремление человека выбирать ситуации риска, опасности и неопределенности и получать от этого новые и более сильные впечатления (связанные с выбросом адреналина).

Имеется анализ корреляции межАу понятиями «ра-

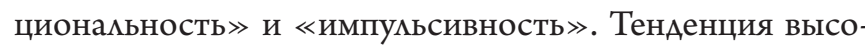
ких показателей по рациональности и низких по импульсивности, и наоборот, была выявлена Т.В. Корниловой и А.А. Аолныковой как на студенческой выборке, так и на выборке преподавателей [1].

Многие виды спорта связаны с постоянной готовностью к риску. Если рассматривать Аанное понятие более широко, то оно может отражать общую установку Аействовать по отношению к различным неопределенным, рискованным ситуациям. Наличие готовности разрешать проблемные ситуации в первую очередь говорит о Аичностной и социальной зрелости. Полученные Аанные не выявили размичий межАу Авумя группами студентов по шкале «скионности к риску». Это позволяет предполагать, что Аанная характеристика явмяется в большей степени социально воспитуемым и приобретаемым в процессе социализации мичности качеством.

Выводы. По Аанным тестирования выявлено, что у студентов спортивного вуза правый показатель в пробе «перекрест рук» коррелирует с более низкими показателями «импульсивности», испытуемые с разными показателями пробы «перекрест рук» обнаруживают Аостоверные различия по шкале «импульсивность». Это позволяет говорить о наличии инАивиАуаАьных разАичий в особенностях регулятивных функций и показателей импульсивности, связанных с межполушарными асимметриями человека. Полученные результаты могут быть использованы при подготовке спортсменов с учетом их инАивиАуаАьных особенностей [3-9]. 


\section{Список митературы:}

1. Корнилова Т. В. Аиагностика импульсивности и склонности к риску./Т.В. Корнилова, А. А. Аолныкова//Вестник Моск. Ун-та. - Серия 14. - Психология. - 1995. - № 3. - С. 46-56.

2. урия А.Р. Основы нейропсихологии. - М.: ИзА-во МГУ, 1973. - 374 с.

3. Москвин В. А. Межполушарные отношения и проблема индивидуальных размичий. - М.: ИзА-во МГУ, 2002. - 288 с.

4. Москвин В.А., Москвина Н. В. Межполушарные асимметрии и индивидуальные различия человека. - М.: Смысл, 2011.- $368 \mathrm{c}$.

5. Москвин В.А., Москвина Н.В. Психофизиология индивидуальных различий в спорте. - М.: РГУФКСМиТ, 2013. - 128 с.

6. Москвин В.А., Москвина Н. В., Шумова Н. С. Индивидуальные различия в спортивной психологии. - М.: РГУФКСМиТ, 2015.- 134 с.

7. Москвина Н. В. Индивидуальные особенности волевой регуляции (на примере студентов спортивного вуза).//Спортивный психолог. - 2010. - № 3 (21). - С. 44-49.

8. Москвина Н.В. Индивидуальные особенности когнитивных стилей в поведении человека.//Теория и практика прикладных и экстремальных видов спорта. - 2011. - № 2 (21). - С. 20-22.

9. Moskvin V.A., Moskvina N.V. Psychophysiology and features volitional regulation sport university students.//European Journal of Education and Applied Psychology. - 2015. - № 3. - P. $62-65$.

Moskvin Victor Anatolyevich, Russian University of Physical Education, Sport, Youth and Tourism, Dr.Psych., professor of psychology department of RSUPhCSYT E-mail:1700018v@mail.ru

Moskvina Nina Victorovna, Ph.D., associate professor of psychology department Shumova Natalya Sergeyvna, Ph.D., associate professor of psychology department Kovalevski Andrey Grigoryevich, postgraduate student of psychology department

\section{Control over the actions in sports psychology}

Abstract: The features of monitoring the operation of the example sports university students (boys and girls 16-17 years old, $n=78$ ) with different signs of brain asymmetry in the regulatory unit of A. Luria. For the diagnosis of strong-willed regulation used "Scale control action" of Kuhl J. Identified the individual characteristics of the control of the action due to brain asymmetry.

Keywords: sport, asymmetry, individual differences, control of action.

Москвин Виктор Анатольевич, Российский государственный университет физической культуры, спорта, молодежи и туризма,

д. псх.н., профессор кафедры психологии

E-mail: 1700018v@mail.ru

Москвина Нина Викторовна, к. псх. н., доцент кафедры психологии

Шумова Наталия Сергеевна, к. псх. н., дочент кафедры психологии

Ковалевский Андрей Григорьевич, аспирант кафедры психологии РГУФКСМиТ

\section{Контроль за действием в спортивной психологии}

Аннотация: Изучены особенности контромя за действием на примере студентов спортивного университета (юноши и девушки 16-17 мет, $\mathrm{n}=78$ ) с разными признаками асимметрии регумятивного блока мозга по 